\title{
Aromatics production from lignocellulosic biomass: shape selective dealkylation of lignin-derived phenolics over hierarchical ZSM-5
}

\author{
Yuhe Liao $^{a}$, Ruyi Zhonga ${ }^{\mathrm{a}}$, Martin d'Halluin ${ }^{\mathrm{a}}$, Danny Verboekend ${ }^{\mathrm{a}, *, \uparrow}$, Bert F. Sels ${ }^{\mathrm{a}, *}$ \\ ${ }^{a}$ Centre for Sustainable Catalysis and Engineering, KU Leuven, Celestijnenlaan 200F, 3001 Heverlee, Belgium \\ ${ }^{\dagger}$ Present address: Zeopore Technologies NV, Lelielaan 4, 3061 Bertem, Belgium \\ *Email: bert.sels@kuleuven.be; danny.verboekend@kuleuven.be \\ KEYWORDS. lignin, phenol, hierarchical zeolites, activity, stability, shape selectivity
}

\begin{abstract}
The selective conversion of lignin or lignin-derived products into bulk chemicals is the foremost challenge for nearfuture lignocellulosic biorefineries. This study investigates the production of phenol and propylene from lignin-derived 4- $n$ propylphenol (4-n-PP) via gas-phase dealkylation over hierarchical ZSM-5 zeolites in the presence of steam. A series of hierarchical ZSM-5 zeolites with different degrees of mesoporosity and acid properties were prepared by alkaline treatment and mild acid washing. The catalytic evaluation reveals a predominant contribution of the strong acid sites to the dealkylation catalysis. Hierarchization of ZSM-5 zeolites via desilication in alkaline generates Lewis acid sites and reduces the amount of strong Brønsted acid sites. Despite their higher activation energy for dealkylation, reactions on the Lewis acid sites are faster at the thermodynamically required high temperature due to a larger entropic contribution to activation on these sites. In addition to the high catalytic activity, the hierarchical zeolites preserve the high phenol and propylene selectivity as bimolecular side reactions such as disproportionation, transalkylation and some C-C cleavage pathways were inhibited. This observation suggests that both the strong Lewis and Brønsted acid sites are located in confined spaces in which selectivity is determined by transition state shape selectivity. The catalytic stability is improved upon hierarchization as the results of lowering of the total amount of strong acid sites and prevention of substantial product diffusion issues (caused by shortening of diffusion paths). Therefore, dealkylation over mesoporous zeolites can be processed under lower water partial pressure.
\end{abstract}

Shape selective catalysis with microporous zeolites plays a vital role in current oil refinery. ${ }^{1-3}$ Most well-known family of shape selective zeolites feature the mordenite framework inverted (MFI) topology, of which ZSM-5 is the most renowned member. Its commercial utilizations in e.g., aromatic alkylation, xylene isomerization, cracking, and methanol-to-hydrocarbons (including aromatics) have been reported. ${ }^{1,4}$ The molecule size of the aromatic products in these processes is usually smaller than that of certain trimethylbenzene isomers due to the confinement effect imposed by the micropores of the MFI structure (pores: $5.1 \times 5.5 \AA$, $5.3 \times 5.6 \AA$ ).${ }^{5}$ Usage of zeolites, including the beneficial role of shape selective catalysis, has also been recognized in biomass conversion. ${ }^{6-11}$ For instance, ZSM-5 shows shape selective properties in the cracking of biomass-related oil, pyrolysis of glucose and lignocellulose, and hydrogenation of triacylglycerols. ${ }^{12-18}$

Though beneficial for the product selectivity, the sole presence of micropores in the zeolite crystal may cause restrictive active sites accessibility and mass diffusion limitations, reducing the utilization efficiency of the microporous crystal. ${ }^{19}$ Hierarchical porous architectures, presenting a well-interconnected network of micro- and mesopores, are capable of circumventing these disadvantages. Accordingly, hierarchical zeolites show an enhancement of the active sites accessibility and shortening of the diffusional paths throughout the crystal, as reported in the petroleum chemistry and biomass upgrading. ${ }^{19-26}$ For instance, hierarchical ZSM-5 shows higher activity and selectivity for benzene ethylation to ethylbenzene than the microporous ZSM5. ${ }^{27-28}$ The catalytic activity of hierarchical ZSM-5 for isomerization of $o$-xylene is also higher, but a decrease of $p$ xylene selectivity is observed due to a reduced effect of the (product) shape selectivity in the mesoporous zeolite structure. ${ }^{29}$ Analogue advantages were demonstrated for the catalytic fast pyrolysis of lignocellulose with hierarchical ZSM5. Hierarchization led to higher aromatics yield and less coke and char formation as the results of enhanced accessibility and shorter product diffusion path. ${ }^{22,30}$

Generally, two synthetic strategies are identified: top-down and bottom-up, to introduce mesoporosity into the microporous zeolite crystal. ${ }^{19,31-32}$ Top-down approaches relate to application of (sequences of) post-modifications of conventional microporous zeolites by alkaline (with strong or mild bases, such as $\mathrm{NaOH}^{31,33-35}$ and $\mathrm{NH}_{4} \mathrm{OH}^{25-26}$ ), acid, and steam treatment ${ }^{19}$. Bottom-up methods refer to modification of the hydrothermal synthesis protocol such as using specific organic structure-directing templates to create a network of mesoporous channels. The bottom-up method usually features technical challenges including low synthesis concentration, expensive templates, long synthetic time, low hydrothermal stability, which constrains its commercial prospect, but they are unique instruments to study more deeply the hierarchization effect on catalysis. ${ }^{36-37}$ Although the top-down approach is always accompanied by extra step and loss of material, its versatility 
and ease of implement enable it more applicable to the industrial scale. ${ }^{31,36}$

In the context of lignocellulose conversion, cellulose utilization has been extensively studied, ${ }^{38-42}$ but valorization of lignin is still one of the key challenges. Lignin, an alkyl phenolics biopolymer, around $15 \mathrm{wt} . \%$ to $40 \mathrm{wt} . \%$ present in lignocellulose, may serve as an ideal renewable carbon source, specifically for aromatics production, rather than being directly burned for energy. ${ }^{43-44}$ Since lignin contains versatile functional groups besides those present in most aromatic chemical products such as BTX, phenol and catechol, ${ }^{45}$ selective defunctionalization strategies are entailed to obtain aromatic chemicals from lignin. ${ }^{8}$ Harsh processing conditions can be applied directly on the biomass, but they are usually accompanied with a lot of heavy tars and light gases. ${ }^{46}$ Selective depolymerization of lignin into a few structurally similar monomers with high yields is more attractive but challenging. Recent protection strategies processing in planta lignin under relatively mild conditions showed high yields of several phenolic chemicals. ${ }^{43,}{ }^{47-66}$ Such lignin-first, and in particular the reductive catalytic fractionation (RCF) strategies, are very promising. They selectively produce, for example, 4- $n$-propylguaicol (PG) and 4-n-propylsyringol (PS) from raw wood lignin. Lignin-first concepts have currently being extensively investigated to define not only the role and stability of the catalysis or the feedstock type, but also the technological advancements with regard to up-scaling and continuous processing in recent literature among others. $^{43,47-55,57-59,67}$

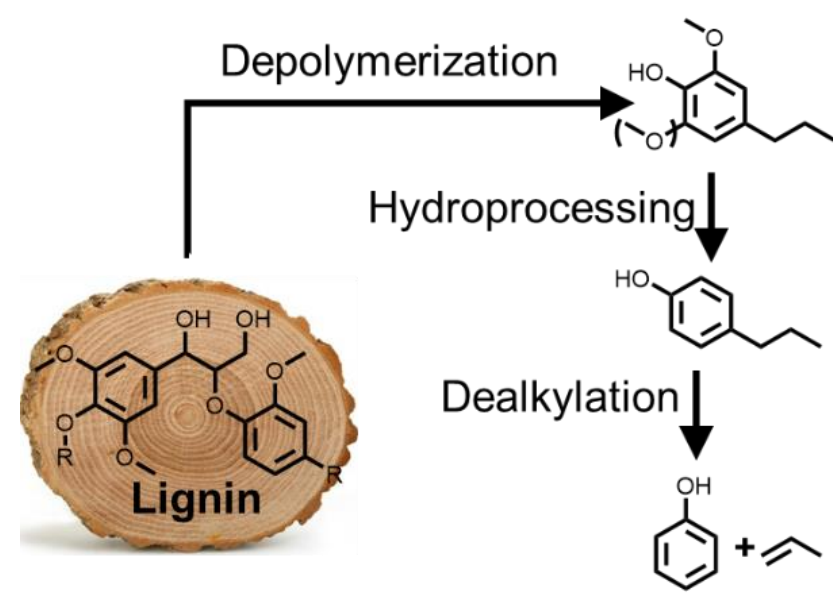

Scheme 1. Conversion of lignin toward phenol and propylene.

Considering the chemical structure of the lignin-first derived phenolic molecules and the specific pore architecture of zeolites like ZSM-5, the application of zeolites to further upgrade lignin-derived phenolics into useful aromatics such as biophenol, along with other valuable co-products like methanol and propylene, may be an excellent choice. In this context, we recently demonstrated that commercial microporous ZSM-5 zeolites act as a selective catalyst for almost quantitative dealkylation of 4- $n$-propylphenol (4- $n$-PP), ${ }^{68-70}$ which can be obtained by PG or PS hydroprocessing, into phenol and propylene (Scheme 1). ${ }^{71-72}$ The high product yield is attributed to the existence of transition state shape selectivity of ZSM-5. However, rapid catalyst deactivation by pore blocking due to coking/bulky molecules restricts long catalyst service times, except with co-fed of large quantities of water, but the latter could infringe the structural integrity of the zeolite on the long term. ${ }^{73}$ Besides, it has been shown that alkylphenols stream obtained from hydroprocessing of lignin-first derived monomers contains not only 4- $n$-propylphenol, but also more sterically demanding molecules such as propylcresols and 3- $n$ propylphenols and impurities such as $n$-propylbenzene. Hierarchical ZSM-5 zeolite is required to deal with these sterically demanding alkylphenols and impurities. ${ }^{71}$ Nevertheless, the precise role of hierarchization and the importance of the acid properties are not studied, to the best of our knowledge.

Hence, in this work, a series of hierarchical ZSM-5 zeolites were prepared via alkaline treatment of commercial highly

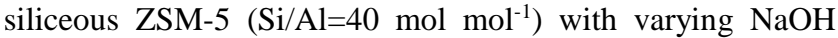
concentrations, followed by acid washing with $\mathrm{HCl}$. The influence of mesoporosity introduction on the catalytic activity, selectivity, and catalytic stability of ZSM-5 was investigated in detail in the dealkylation. Pure 4-n-PP was selected as substrate to avoid the complexity of the real alkylphenols obtained from hdyroprocessing of lignin-first derived monomers. It is demonstrated that hierarchization can improve the activity and stability of ZSM-5. The role of water in the stable catalysis is revisited here for hierarchical zeolites. These results highlight the importance of performing a kinetic study to evaluate hierarchical zeolites. This work shows promising opportunities to valorize biomass-derived oxygenates over hierarchical zeolites.

Results and discussion

Zeolite catalysts and their properties. Post-modification conditions and material yields for alkaline treatment (with varying base concentrations) and subsequent mild acid washing with $\mathrm{HCl}$ are provided in the experimental section and Table S1.

The alkaline treated samples ZSM-5-H show increased uptake at middle-to-high-relative pressures (Figure S1), which indicates the co-presence of micropores and mesopores. The shift to larger pore sizes with the increase of base concentration of the post-treatment, as shown by the corresponding size distribution plots (Figure S1), is accounted for by the formation of mesopores. The conventional (ZSM-5-P) and all hierarchical samples (ZSM-5-H) show XRD patterns characteristic of the MFI structure (Figure S2). As expected, the diffraction peak intensity of the hierarchical zeolites is lower than that of the conventional sample, and the intensity lowers with the alkaline concentration of the post-treatment, in accordance with the size reduction of the crystalline domain upon hierarchization by alkaline treatment, as well as by formation of some amorphous species. $^{35,74}$

Quantified porosity and acid properties of ZSM-5-P and the various hierarchical ZSM-5-H samples are summarized in Table 1. The volume of the micropores $\left(V_{\text {micro }}\right)$ decreases continuously, from 0.11 to $0.06 \mathrm{~cm}^{3} \mathrm{~g}^{-1}$, with the alkaline concentration increasing from 0 to $0.4 \mathrm{M}$, while the mesopores volume $\left(V_{\text {meso }}\right)$ increases substantially, from 0.13 to $0.81 \mathrm{~cm}^{3} \mathrm{~g}$ 1. $S_{\text {meso }}$, presenting the mesopore and external surface area, increases gradually from 166 to $282 \mathrm{~m}^{2} \mathrm{~g}^{-1}$ for the conventional and hierarchical samples, up to the sample ZSM-5-H-0.3M. $S_{\text {meso }}$ is not further improved in ZSM-5-H-0.4M due to excessive zeolite leaching. Acid washing only slightly improves $S_{\text {meso }}$ and $V_{\text {meso }}$, as illustrated for instance by comparison of ZSM-5-H-0.2M-HCl and ZSM-5-H-0.2M. All these trends are consistent with previous reports on ZSM-5 base postmodification. $^{35,75}$ 
Table 1. Porosity and acidity of ZSM-5 zeolites.

\begin{tabular}{|c|c|c|c|c|c|c|c|c|c|c|}
\hline \multirow{3}{*}{ Sample } & \multirow{3}{*}{$\begin{array}{l}\mathrm{BET}^{a} / \\
\mathrm{m}^{2} \mathrm{~g}^{-1}\end{array}$} & \multirow{3}{*}{$\begin{array}{l}V_{\text {meso }}^{b} / \\
\mathrm{cm}^{3} \mathrm{~g}^{-1}\end{array}$} & \multirow{3}{*}{$\begin{array}{l}V_{\text {micro }}{ }^{b} / \\
\mathrm{cm}^{3} \mathrm{~g}^{-1}\end{array}$} & \multirow{3}{*}{$\begin{array}{l}S_{\text {meso }}^{b} / \\
\mathrm{m}^{2} \mathrm{~g}^{-1}\end{array}$} & \multicolumn{2}{|c|}{$423 \mathrm{~K}$} & \multicolumn{2}{|c|}{$523 \mathrm{~K}$} & \multicolumn{2}{|c|}{$623 \mathrm{~K}$} \\
\hline & & & & & $C_{\mathrm{B}}^{c} /$ & $C_{\mathrm{L}}^{c} /$ & $C_{\mathrm{B}}^{c} /$ & $C_{\mathrm{L}}^{c} /$ & $C_{\mathrm{B}}{ }^{c} /$ & $C_{\mathrm{L}}^{c} /$ \\
\hline & & & & & $\begin{array}{c}\mu \mathrm{mol} \mathrm{g}^{-1} \\
\left.(\%)^{\mathrm{d}}\right)\end{array}$ & $\begin{array}{c}\mu \mathrm{mol} \mathrm{g}^{-1} \\
\left.(\%)^{\mathrm{d}}\right)\end{array}$ & $\begin{array}{c}\mu \mathrm{mol} \mathrm{g}^{-1} \\
\left(\%^{\mathrm{d}}\right)\end{array}$ & $\begin{array}{c}\mu \mathrm{mol} \mathrm{g}^{-1} \\
\left(\%^{\mathrm{d}}\right)\end{array}$ & $\begin{array}{c}\mu \mathrm{mol} \mathrm{g}^{-1} \\
\left(\%^{\mathrm{d}}\right)\end{array}$ & $\begin{array}{c}\mu \mathrm{mol} \mathrm{g}^{-1} \\
\left.(\%)^{\mathrm{d}}\right)\end{array}$ \\
\hline ZSM-5-P & 368 & 0.13 & 0.11 & 166 & $174(100)$ & $37(100)$ & $165(95)$ & $18(49)$ & $162(93)$ & $8(44)$ \\
\hline $\begin{array}{c}\text { ZSM-5-H- } \\
0.1 \mathrm{M}\end{array}$ & 379 & 0.19 & 0.10 & 189 & $172(100)$ & $66(100)$ & $165(96)$ & $57(87)$ & $154(90)$ & $34(51)$ \\
\hline $\begin{array}{c}\text { ZSM-5-H- } \\
0.2 \mathrm{M}\end{array}$ & 425 & 0.39 & 0.09 & 259 & $156(100)$ & $104(100)$ & $141(90)$ & $83(80)$ & $127(81)$ & $52(50)$ \\
\hline $\begin{array}{l}\text { ZSM-5-H- } \\
0.2 \mathrm{M}-\mathrm{HCl}\end{array}$ & 482 & 0.43 & 0.10 & 278 & 159 (100) & $50(100)$ & $155(97)$ & $41(82)$ & $152(96)$ & $33(66)$ \\
\hline $\begin{array}{c}\text { ZSM-5-H- } \\
0.3 \mathrm{M}\end{array}$ & 435 & 0.66 & 0.08 & 282 & $125(100)$ & $144(100)$ & $103(82)$ & $116(81)$ & 73 (58) & $61(42)$ \\
\hline $\begin{array}{c}\text { ZSM-5-H- } \\
0.4 \mathrm{M}\end{array}$ & 396 & 0.81 & 0.06 & 282 & 129 (100) & $157(100)$ & 98 (76) & 118 (75) & $67(52)$ & $74(47)$ \\
\hline
\end{tabular}

$\bar{a}$ determined by $\mathrm{N}_{2}$ sorption; ${ }^{b} t$-plot was used to determine the $V_{\text {micro }}$ and $S_{\text {meso }}, V_{\text {meso }}=V_{\text {pore }}-V_{\text {micro }}$, where $V_{\text {pore }}$ is the total volume (adsorption value at $\left.p / p_{0}=0.97\right), S_{\text {meso }}$ includes mesopore and external surface area; ${ }^{c}$ determined by pyridine FTIR; ${ }^{d} \%$ of site number remaining after evacuation ( $1 \mathrm{mbar}$ ) at the given temperature, compared to the value determined at $423 \mathrm{~K}$.

Besides porosity, acid properties play a vital role in catalysis, ${ }^{76}$ and they are therefore characterized and defined. $\mathrm{NH}_{3}$-TPD was used to analyze the strength of acid sites, while pyridine probe FTIR is able to distinguish between Brønsted and Lewis acids, and allows quantification of their number and strength. The Brønsted acid sites density $\left(C_{\mathrm{B}}\right)$ consistently decreases (almost linearly) with the alkaline concentration in expense of a significant enhancement of the Lewis acid sites density $\left(C_{\mathrm{L}}\right)$ (Figure 1). This can be explained by the redistribution of Alspecies upon alkaline treatment. ${ }^{75,77-78}$ The loss of Brønsted acid sites is slightly overcompensated by the newly-formed Lewis acid sites, and the total acidity becomes therefore slightly higher than that of the parent ZSM-5-P sample. This overcompensation may be caused by the improved accessibility

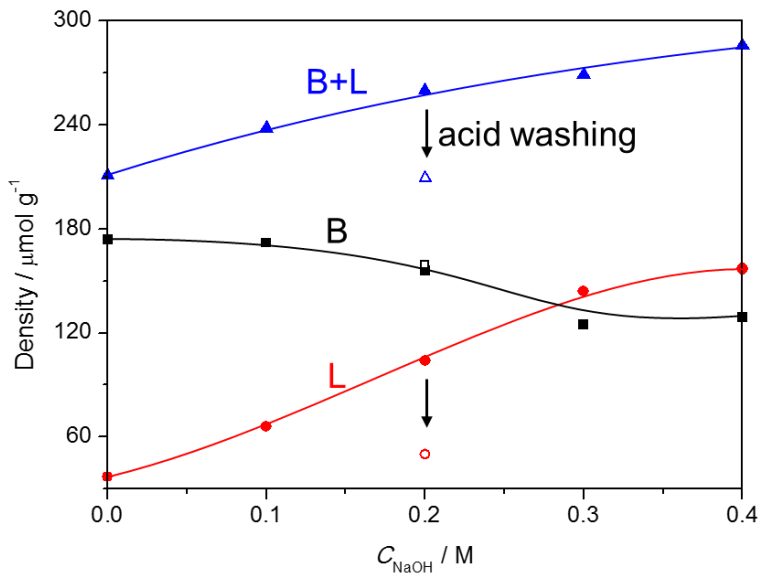

Figure 1. The Brønsted (B), Lewis (L), and total $(\mathrm{B}+\mathrm{L})$ acid sites density (determined by pyridine FTIR at $423 \mathrm{~K}$ ) as a function of $\mathrm{NaOH}$ concentration $\left(C_{\mathrm{NaOH}}\right)$ used for posttreatment. The hollow symbols are acid washed sample.

to the acid sites, though one should be cautious with experimental errors in quantifying the different acid site types.
Despite the formation of Lewis acid sites, zeolites treated with mild alkalinity $(\leq 0.2 \mathrm{M})$ predominantly contain Brønsted acid sites, while Lewis acid sites dominate in zeolites contacted with alkalinity above $0.2 \mathrm{M}$. The Lewis acid sites can be partly removed upon mild $\mathrm{HCl}$ acid washing, while the Brønsted acid sites are well preserved. This is illustrated in the Table 1 and also illustrated in Figure 1 for ZSM-5-H-0.2M, before and after the acid washing.

In addition to the acid density, the acid strength was analyzed and evaluated. Figure $\mathrm{S} 3$ shows the $\mathrm{NH}_{3}$-TPD profiles (and their deconvolutions) of different ZSM-5 samples. Alkaline treatment of ZSM-5-P clearly increases the percentage of weak acids sites (Table S2, $T_{573}$ ). The presence of the weak acid sites are most likely associated to the generated Lewis acid sites at the expense of the Brønsted acid sites. A clear linear relationship between the number of the weak sites, using the integrated data of the low temperature signal of the $\mathrm{NH}_{3}-\mathrm{TPD}$ plot (Table S2), and the amount of Lewis sites, calculated from the FTIR experiment, is indeed obtained (Figure S4). The acid strength of the remaining Brønsted acid sites stays high for zeolites treated with mild alkalinity; more than $90 \%$ of the Brønsted acid sites comprises of the strong sites (Table 1). The situation is different for zeolites modified with strong alkalinity. Here, only about $50 \%$ of the total acid sites belongs to the category of the strong acid sites.

In summary, a defined set of ZSM-5 zeolites are available for the catalytic tests, with variations in porosity properties and surface area, and in acid density and strength properties.

Catalysis and role of hierarchization. Catalytic dealkylation of 4- $n$-PP (to phenol and propylene; see Scheme 1) over the parent and post-modified samples were conducted in a fixedbed reactor in a temperature range from 473 to $743 \mathrm{~K}$, at two different contact times, viz. $3.7 \mathrm{~h}^{-1}$ and $55.5 \mathrm{~h}^{-1}$ WHSV. Temperature dependency of the conversion and selectivity was investigated by using practical light-off experiments. Their reliability is verified by sufficient similarity of the conversion rate and selectivity values with steady-state values of single 
temperature experiments at different contact times (see e.g., the star symbols in Figure 2). Two different contact times were tested to distinguish thermodynamic and kinetic effects in the temperature range. The higher conversion rates with increasing temperature follow Arrhenius law, but the dealkylation of $n$-PPs is thermodynamically limited in the studied temperature range. The equilibrium shifts to the products with increasing temperature, as expected for endothermic reaction. The systematic significantly lower conversion rate at the lower contact time proves that kinetics are investigated far from the equilibrium at $55.5 \mathrm{~h}^{-1}$ WHSV. Data analysis at low conversions (differential mode) allows to investigate the kinetics of the catalytic experiments in the fixed-bed reactor.
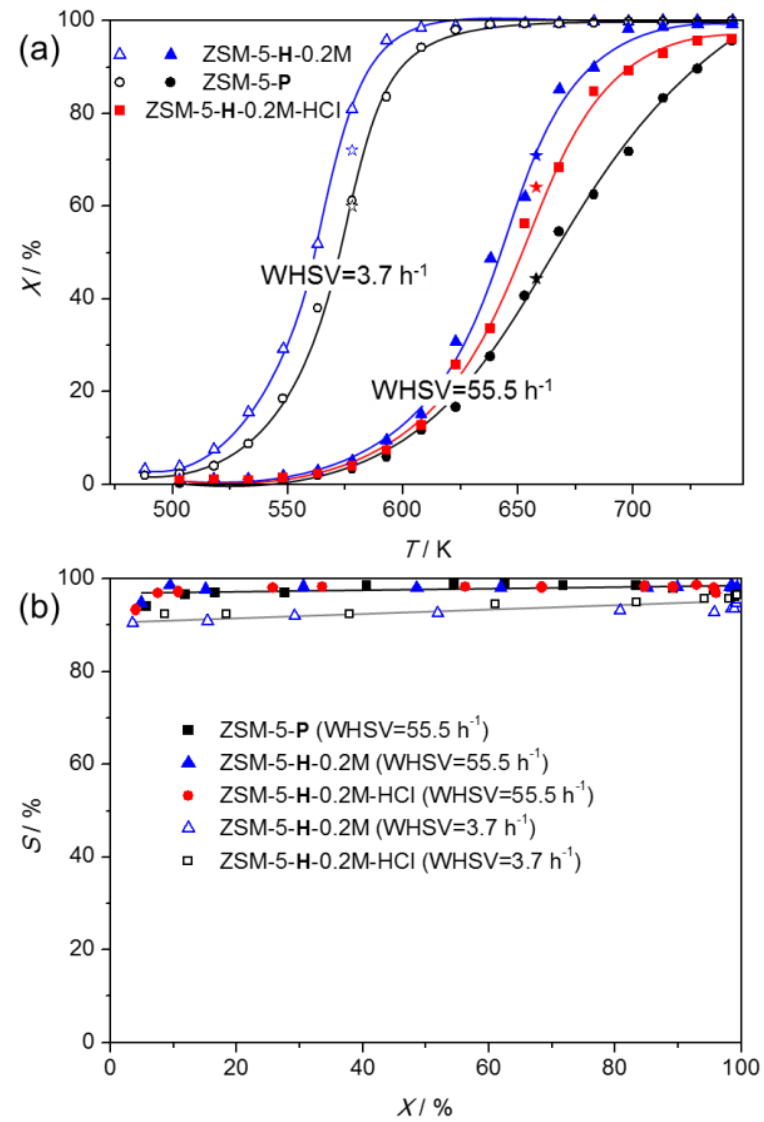

Figure 2. (a) Conversion $(X)$ of $n$-PPs as a function of temperature $(T)$ and (b) selectivity $(S)$ to phenol and propylene as a function of conversion $(X)$ in the dealkylation of 4- $n$-PP over ZSM-5-P, ZSM-5-H-0.2M, and ZSM-5-H-0.2M-HCl at low $\left(3.7 \mathrm{~h}^{-1}\right)$ and high $\left(5.5 \mathrm{~h}^{-1}\right) \mathrm{WHSV}$. Ramping rate $=1 \mathrm{~K} \mathrm{~min}^{-}$ ${ }^{1}$, water/4- $n-\mathrm{PP}=6$. The star symbols in (a) are the data obtained from single temperature experiments with time on stream (taken after 4 hours). In (b), the conversion was varied by increasing the temperature. Note: since ZSM-5 can also dealkylate the isomers of $4-n-\mathrm{PP}$, the conversion is the conversion of all isomers (n-PPs) here.

Firstly, inspection of the conversion rate reveals a higher catalytic activity after hierarchization. This is for instance apparent by comparing the data of ZSM-5-H-0.2M and ZSM5-P at both contact times (Figure 2a). The difference is obviously more pronounced at the low contact time $\left(55.5 \mathrm{~h}^{-1}\right.$ WHSV). The rate improvement is most significant for the samples treated under mild alkaline conditions, viz. $0.2 \mathrm{M}$ $\mathrm{NaOH}$, indicating that there is an optimal modified catalyst with certain acid composition/properties and pore structure (Figure S5). Washing the base-treated catalyst with $\mathrm{HCl}(0.1 \mathrm{M})$ selectively removes (extraframework) Al (related to Lewis acid sites), and that clearly reduces the catalytic activity. This result accords with previous observation, suggesting that Lewis acids, which are removed here by the acid washing, are also able to catalyze the dealkylation of alkylphenols. ${ }^{69}, 79$ Although the total acidity and the corresponding acid strength of ZSM-5-H$0.2 \mathrm{M}-\mathrm{HCl}$ are fairly similar to the parent sample ZSM-5-P, ZSM-5-H-0.2M-HCl gives higher conversion rates (Figure 2a). Besides the effect on activity, hierarchization of zeolites may impact the products selectivity, especially for the shape selective sensitive reactions. ${ }^{80}$ Figure $2 \mathrm{~b}$ shows the product selectivity (to phenol and propene) at different conversions (at different contact times and temperatures) for the tested catalysts. More details about the product distribution at each conversion/temperature is available in Figure S5. There are no clear indications that the chemistry, as reported for non-treated microporous ZSM-5, ${ }^{69-70}$ proceeds differently in the presence of hierarchical zeolite samples. Isomerization is a fast reaction and occurs favorably at low temperature, showing the formation of $n$-propylphenol isomers, whereas iso-propylphenol isomers were hardly observed for all samples (Figure S5). Bimolecular reactions such as transalkylation and disproportionation are thermodynamically favored at low to intermediate temperature, but the corresponding dipropyl phenolic products were seldom observed. This agrees well with the existence of transition state shape selectivity as the result of the specific pore structure of MFI topology. ${ }^{70}$ High temperature allows dealkylation, which selectively occurs in the confined spaces of ZSM-5 according to a monomolecular mechanism. For the same reason the bimolecular cracking pathways were not observed here with the hierarchical ZSM-5 samples, e.g., no significant cresols formation is observed, as opposed to reported data of USY and $\gamma$-alumina. ${ }^{69-70}$ Figure $2 \mathrm{~b}$ shows that the selectivity is slightly lower at the high contact time (3.7 $\left.\mathrm{h}^{-1} \mathrm{WHSV}\right)$ in comparison to low contact time $\left(55.5 \mathrm{~h}^{-1} \mathrm{WHSV}\right)$ due to inhibition of the side reactions at low contact time.

Overall, it seems that hierarchization has only little impact on the product selectivity of $n$-PPs dealkylation. As the high phenol selectivity is controlled by the occurrence of transition state shape selectivity, it may be concluded that the introduction of mesopores does not have a significant influence on the local confinement of the remaining active sites. This also suggests that both the majority of Brønsted sites and Lewis acid sites are located in sufficiently confined spaces such as micropores and micropore mouths. Such space is too small to allow the bimolecular reactions such as disproportionation, transalkylation (to form dipropylphenols) and C-C cracking (to form cresols), but large enough to accommodate the monomolecular reactions and to exert the transition state shape selective effect.

The kinetics of the dealkylation reaction (at $55.5 \mathrm{~h}^{-1}$ WHSV) were studied into more detail by expressing the conversion rates in turnover frequencies (per total acid site, Brønsted and Lewis acid sites; $\mathrm{TOF}_{\text {tot }}, \mathrm{TOF}_{\mathrm{BA}}$ and $\mathrm{TOF}_{\mathrm{LA}}$ ) using the amount of acid sites determined by the pyridine FTIR experiment (Table 1). Before performing the kinetic study, control experiments and calculations were done to rule out external, inter- and intracrystalline diffusion limitations, as reported before. ${ }^{69-70}$ Since hierarchization of ZSM-5-P reduces the average size of the crystalline domain, diffusion limitations can also be excluded for the mesoporous ZSM-5-H samples. 
ZSM-5-P, ZSM-5-H-0.2M and ZSM-5-H-0.2M-HCl clearly show different reaction rates, but a similar apparent activation energy, around $100 \mathrm{~kJ} \mathrm{~mol}^{-1}$ (Figure S6). This high value supports the absence of diffusion limitations in both ZSM-5-P and ZSM-5-H. Such observation has also been reported for $n-$ hexane cracking over conventional and hierarchical ZSM-5, and propane cracking over conventional and hierarchical SAPO-5. ${ }^{75,81}$ Since 4- $n$-PP can enter the micropores of ZSM-5 and there is no diffusion limitations under the applied reaction circumstances, the different catalytic activity (on per acid site basis) between microporous and hierarchical ZSM-5 cannot be ascribed to differences in mass diffusion (as corroborated by the equal apparent activation energy) and accessibility issues (since sites probed by pyridine were used).
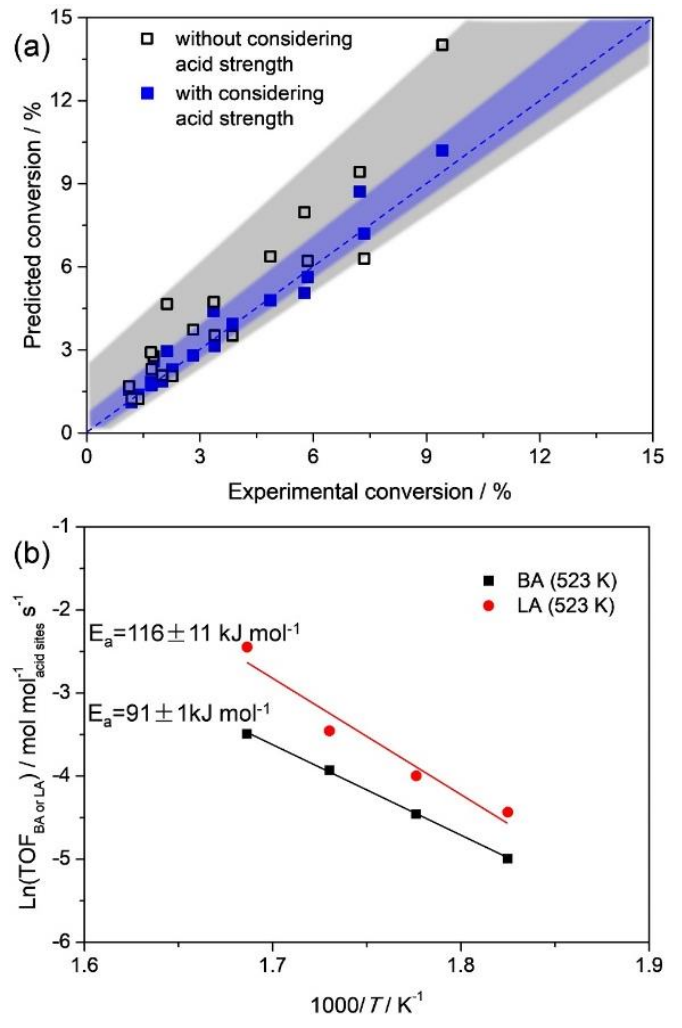

Figure 3. (a) Predicted conversion of $n$-PPs versus experimental conversion of $n$-PPs; (b) Turnover frequency (TOF) of $n$-PPs dealkylation over Brønsted acid (BA) sites and Lewis acid (LA) sites, with the indication of activation energy. The densities of Brønsted and Lewis acid sites measured at $523 \mathrm{~K}$ (the kinetic study was conducted between $548 \mathrm{~K}$ and $593 \mathrm{~K}$ ) and $423 \mathrm{~K}$ were used to predict the conversion and calculate the TOF for with and without considering acid strength, respectively.

The difference might be caused by alterations of the intrinsic activity of the acid sites, that is the efficiency of the present active sites to facilitate the reaction, as the acid properties (the acid amount and strength of BA and LA) of ZSM-5 are changed after hierarchization (Table 1 and Figure S3). To elaborate on this hypothesis, an attempt was done to estimate the kinetics on per Brønsted and Lewis acid site basis, while taking into account the strength of the sites. An iterative approach was done to obtain the best fit for the overall conversion rate by summation of the conversion rate per Brønsted and Lewis acid site, viz. rate $_{\mathrm{tot}}=$ rate $_{\mathrm{BA}}+$ rate $_{\mathrm{LA}}$ (see supporting information), considering the amount of the acid sites and their various acid strengths, as measured by the pyridine FTIR experiment. Various data points of the different ZSM-5-H samples were used to achieve the fitting. An illustration of the fits assuming all acid sites (hollow symbols) or only the strong Brønsted and Lewis acid sites (solid symbols) contributed to catalysis is presented in a parity plot in Figure 3 a.

The best fitting was obtained by considering only the strong acid sites (solid symbols, Figure 3a), showing an apparent activation energy of $91 \pm 1$ and $116 \pm 11 \mathrm{~kJ} \mathrm{~mol}^{-1}$ for Brønsted and Lewis acid sites, respectively (Figure $3 b$ ). The higher value for the Lewis acid sites agrees well with previous reports for dealkylation chemistry; for instance, $98 \mathrm{~kJ} \mathrm{~mol}^{-1}$ has been measured for Brønsted acid catalysts, while $153 \mathrm{~kJ} \mathrm{~mol}^{-1}$ was observed for $\gamma$-alumina. ${ }^{70}$ Although Lewis acid sites have higher activation energy, they are clearly more active for $n$-PPs dealkylation than Brønsted acid sites at the higher temperature range, viz. $>523 \mathrm{~K}$ (Figure $3 \mathrm{~b}$ ), which favors the dealkylation thermodynamically. ${ }^{70}$ The higher rate is ascribed to a higher entropic contribution of activation at the Lewis acid site, compared to that of the Brønsted acid sites (see Eyring plot in Figure S7), causing a significantly stronger rate increase with temperature on the Lewis acid sites. Such difference in kinetic behavior is not unexpected given the different mechanism of activation at the two acid sites (hydride vs. proton), and the potentially different location of the sites in the zeolite.

Although ZSM-5-H-0.4M contains more Lewis acid sites than ZSM-5-H-0.2M, it is slightly less active than the latter. This is attributed to $i$ ) the weakening of the acid site strength (see Table 1 ) as the differences of the amount of Brønsted and Lewis acid sites at $623 \mathrm{~K}$ are larger and smaller, respectively, than those at $523 \mathrm{~K}$, and ii) a lower amount of Brønsted acid sites. The activity decrease of ZSM-5-H-0.2M-HCl compared to ZSM-5H-0.2M (Figure S5) is largely due to the removal of the most active (strong) Lewis acid sites by mild acid washing, while the Brønsted acid sites content is slightly higher. These results emphasize that change in acid strength and amount of active sites is crucial to evaluate the catalytic performance of hierarchical zeolites, next to the pore architecture. The strong acid sites are required to be able to perform the $\mathrm{C}-\mathrm{C}$ cleavage. ${ }^{82}$ Our data seem therefore to infer that zeolites containing strong and confined Lewis acids should be the most active and selective catalyst for the $n$-PPs dealkylation under study.

Besides activity and selectivity, the decay of activity or deactivation of the catalyst was investigated for all samples (at high conversion, viz. $>30 \%$, and same conditions). A typical empirical decay formula was used to describe the loss of activity in function of time on stream (see supporting information). ${ }^{83-84}$ Figure S8 illustrates the time on stream behaviors of different catalysts at $658 \mathrm{~K}$ and $55.5 \mathrm{~h}^{-1}$ WHSV. The data were used to construct the relative activity $v s$. time on stream plots, as presented in Figure 4. The solid lines present the decay fitting.

In agreement with the above activity study, ZSM-5-H-0.2M and ZSM-5-H-0.3M show the highest conversion (Figure S8), as these catalysts contain a high content of Lewis and Brønsted acid sites along with preservation of the high strength of the acid sites. ZSM-5-H-0.1M has less Lewis sites (overcompensating the little higher content of the Brønsted acid sites) and is therefore less active. ZSM-5-H-0.4M has reduced acid strength and Brønsted acid sites, which is also less active compared to ZSM-5-H-0.2M and ZSM-5-H-0.3M. But all hierarchical 
zeolites show higher conversion compared to ZSM-5-P. Figure S8b illustrates the loss of activity upon acid washing as a result of Lewis acid removal. Note that the activity of ZSM-5-H$0.2 \mathrm{M}-\mathrm{HCl}$ remains higher than that of ZSM-5-P, which is due to the higher content of Lewis acid sites (see Table 1), but also a higher stability of the catalysis is observed with that sample, as will be discussed in the following.

The decay curves generally show two different deactivation behaviors: a significant and fast exponential deactivation at the initial stage, followed by a linear deactivation at longer service time. The first deactivation is usually explained by fast coking of the strong acid sites at the external crystal surface and pore mouths, blocking part of the pore entrances, whereas the linear decay is due to gradual pore blockage, $e . g$. due to pore diffusion limitation of large products accumulating within the crystal. ${ }^{83-}$ 84
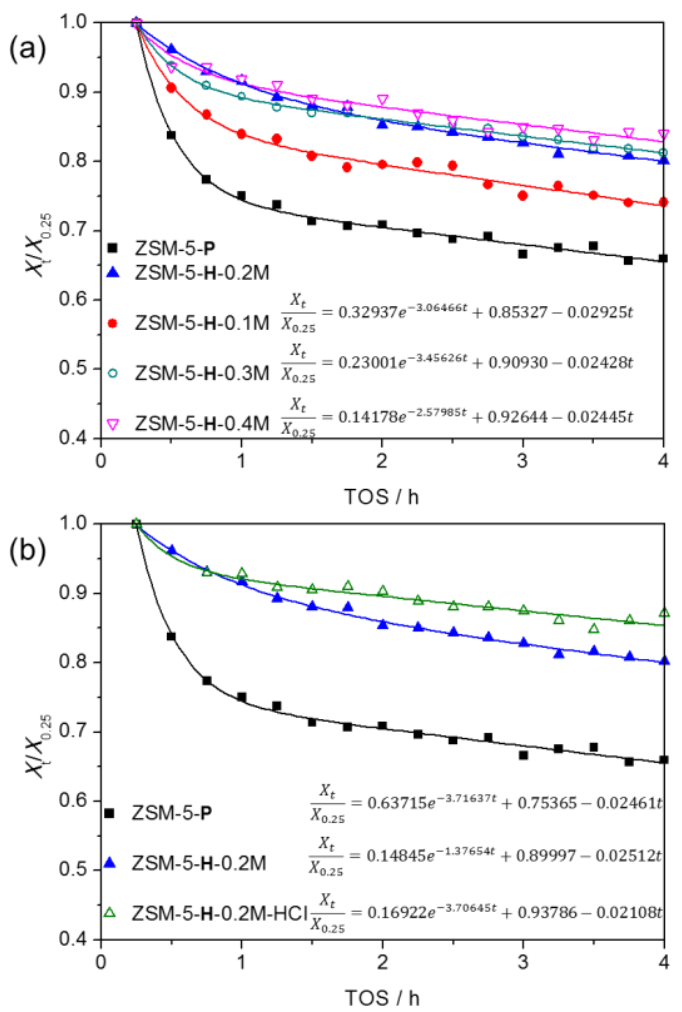

Figure 4. Relative activity $\left(X_{t} / X_{0.25}\right)$ of ZSM-5 zeolites as a function of time on stream (TOS) in the dealkylation of 4- $n$-PP. (A) ZSM-5-P, ZSM-5-H-0.1M, ZSM-5-H-0.2M, ZSM-5-H-0.3M, and ZSM-5-H-0.4M; (B) ZSM-5-P, ZSM-5-H-0.2M, ZSM-5-H-0.2M$\mathrm{HCl}$. WHSV $=55.5 \mathrm{~h}^{-1}$, temperature: $658 \mathrm{~K}$. Water to $4-n-\mathrm{PP}$ is 6 .

It is noticeable that the initial exponential decay decreases with the increase of base concentration during post-treatment. This observation indicates that the hierarchization influences the catalyst coking. For instance, a non-treated ZSM-5-P losses up to $25 \%$ activity in the first one hour, whereas the loss is less than $10 \%$ for ZSM-5-H-0.4M. This may be explained by the lower total amount of strong acid sites (parameter $a$ in Figure S9) in the hierarchical samples (Table 1, $623 \mathrm{~K}$, the total acidity of ZSM-5-H-0.4M is already lower than that of ZSM-5-P). The higher external surface area of the treated catalysts, preventing fast blockage of the pore entrances, may also contribute to the slower deactivation. The linear decrease part shows no significant difference for different samples, which is likely due to the presence of water in the feed, preventing product diffusion (of large compounds such as diphenyl ether that can be formed in the pores in water-poor conditions) and unwanted side reactions that could lead to pore blockage; product diffusion limitation is therefore not a big issue in the presence of steam conditions.

Acid washing further reduces the deactivation rate compared to that of the alkaline treated sample. The initial exponential decay is not significantly influenced by acid washing, but the linear part is significantly reduced (Figures $4 \mathrm{~b}$ and S7). This may be explained by the removal of the most accessible $\mathrm{Al}$ species (that are related to Lewis acid sites). These $\mathrm{Al}$ species can cause coke formation at pore mouth to block the micropores. A similar result that dealumination can improve the catalytic stability has been reported for other cracking reactions. ${ }^{85}$ The TGA analysis of spent catalysts shows indeed that the hierarchical sample ZSM-5-H-0.2M and ZSM-5-H-0.2M-HCl produces less coke than the microporous zeolite ZSM-5-P (Figure S10).
Microporous ZSM-5

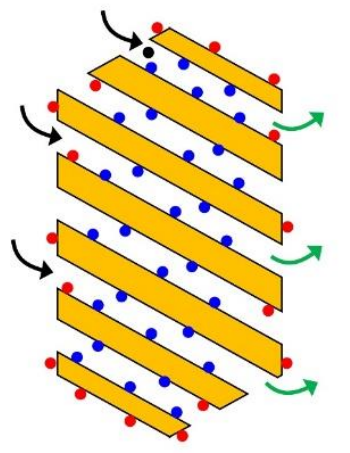

- Lewis acid sites

- Brønsted acid sites
Hierarchical ZSM-5

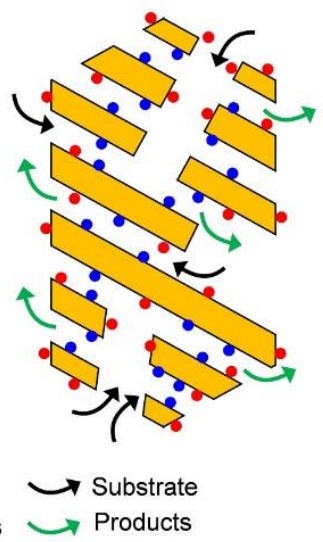

Scheme 2. Schematic representation of diffusion in microporous and hierarchical ZSM-5. The presence of secondary porosity improves the number of pore mouth to diffusion in and out of the micropores, as well as it shortens the diffusion path.

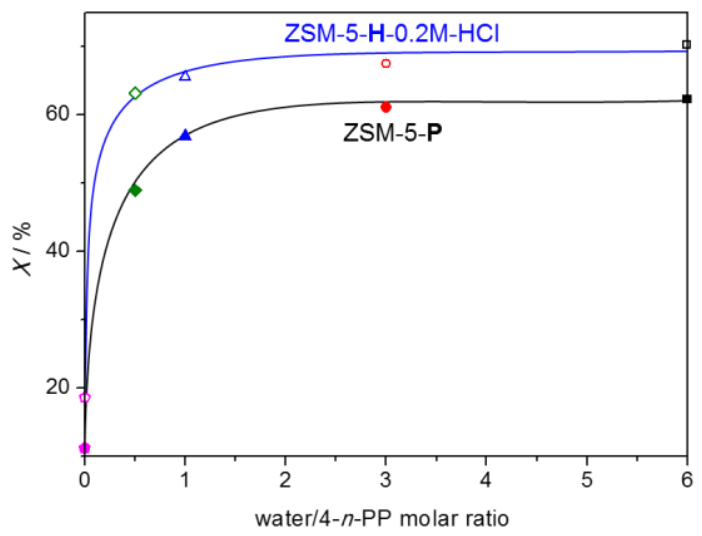

Figure 5. Conversion of $n$-PPs after $4 \mathrm{~h}$ of time on stream as a function of water/4-n-PP molar ratio over ZSM-5-P and ZSM5-H-0.2M-HCl. WHSV=3.7 $\mathrm{h}^{-1}, 578 \mathrm{~K}$.

Our previous study has shown that the fast initial deactivation is largely reduced by the presence of water. ${ }^{68,70}$ The decay of the rate of $n$-PPs dealkylation over ZSM-5-P is much more pronounced in the absence of steam in the feed (Figure S11). Presence of water facilitates the desorption of (alkyl)phenol from the active sites due to a higher adsorption enthalpy of 
water, inhibiting the formation of larger molecules from secondary reactions (such as the dehydration of phenol to diphenyl ether), which would otherwise lead to blockage of transport in the micropores. ${ }^{68,70}$

Since the hierarchical structures have shorter diffusion paths (Scheme 2), such product diffusion limitation should have less impact, and thus lower amounts of water in the feed should be feasible. To investigate this hypothesis, ZSM-P and ZSM-H$0.2 \mathrm{M}-\mathrm{HCl}$ were evaluated for their deactivation sensitivity in the presence of different amounts of water. The results are displayed in Figures 5 and S10.

ZSM-5-H-0.2M-HCl indeed gives always higher conversion with different water to 4- $n$-PP molar ratios than that of ZSM-5$\mathbf{P}$, even in the absence of water (Figures 5 and S10). Besides, ZSM-5-H-0.2M-HCl requires less water to stabilize the catalyst compared to ZSM-5-P (water/4- $n-\mathrm{PP}=0.5$ vs. 1 ). Although for both samples, water can promote the (alkyl)phenol desorption from the active sites, the diffusion paths of (alkyl)phenol in the micropore channel is shorter for the hierarchical sample. Therefore, hierarchical zeolite requires less water to stabilize the activity of alkylphenol dealkylation on stream. In this case, less water will ensure longer time on stream structural stability of zeolites. As generally known, if less water is processed, less energy will be required, for instance for potential waste water treatment in the biorefinery.

\section{Conclusion}

Hierarchical ZSM-5 zeolites, prepared by alkaline treatment, show improved catalytic activity compared to the microporous parent material for dealkylation of 4- $n$-propylphenol to phenol and propylene without compromising the product selectivity. The hierarchization reduces the amount and strength of the Brønsted acid sites and induces a change in $\mathrm{Al}$ sites, leading to the formation of Lewis acids. The strong (and also confined) Lewis acid sites have higher activity than the Brønsted acid sites at sufficiently high temperature, which is the result of larger entropic contribution of activation. Therefore, ZSM-5-H$0.2 \mathrm{M}$, containing high content of Lewis and Brønsted acid sites along with preservation of the high strength of the acid sites, is the highest active catalyst. The smaller amount of strong acid sites and higher external surface area of the hierarchical structures minimize fast deactivation, and therefore less water is required to stabilize long time on stream dealkylation catalysis due to the better diffusion characteristics of the hierarchical material.

\section{ASSOCIATED CONTENT}

\section{Supporting information}

The experimental details, $\mathrm{N}_{2}$ sorption isotherms and pore size distribution, $\mathrm{X}$-ray diffraction patterns, $\mathrm{NH}_{3}$-TPD profiles, TGA analysis, supporting catalytic data.

This material is available free of charge via the Internet at http://pubs.acs.org.

\section{Corresponding Author}

* Email: bert.sels@ kuleuven.be; danny.verboekend@kuleuven.be

\section{Author Contributions}

The manuscript was written through contributions of all authors. All authors have given approval to the final version of the manuscript.

\section{ACKNOWLEDGMENT}

W. Vermandel is thanked for the technical assistance during the catalytic test. Y. L. and D. V. acknowledge China Scholarship Council (201404910467) and FWO for a doctor and postdoc fellowship, respectively. This work was performed in the framework of the IWT-SBO project ARBOREF and BioWood, INTERREG project BIOHArT and Excellence of Science (EoS) project BIOFACT.

\section{ABBREVIATIONS}

4-n-PP, 4-n-propylphenol; $n$-PPs, $n$-propylphenols. FTIR, fourier transformed infrared; $\mathrm{NH}_{3}-\mathrm{TPD}$, ammonia temperatureprogrammed desorption; WHSV, weight hourly space velocity.

\section{REFERENCES}

1. Vermeiren, W.; Gilson, J. P., Impact of Zeolites on the Petroleum and Petrochemical Industry. Topics in Catalysis 2009, 52 (9), 1131-1161. 10.1007/s11244-009-9271-8.

2. Smit, B.; Maesen, T. L., Towards a molecular understanding of shape selectivity. Nature 2008, 451 (7179), 671 8. 10.1038/nature06552.

3. Degnan Jr, T. F., The implications of the fundamentals of shape selectivity for the development of catalysts for the petroleum and petrochemical industries. Journal of Catalysis 2003, 216 (1-2), 32-46. 10.1016/S0021-9517(02)00105-7.

4. Degnan, T. F.; Chitnis, G. K.; Schipper, P. H., History of ZSM-5 fluid catalytic cracking additive development at Mobil. Microporous and Mesoporous Materials 2000, 35-6, 245-252. 10.1016/S1387-1811(99)00225-5.

5. Csicsery, S. M., Shape-Selective Catalysis in Zeolites. Zeolites 1984, 4 (3), 202-213. 10.1016/0144-2449(84)90024-1.

6. $\quad$ Ennaert, T.; Van Aelst, J.; Dijkmans, J.; De Clercq, R.; Schutyser, W.; Dusselier, M.; Verboekend, D.; Sels, B. F., Potential and challenges of zeolite chemistry in the catalytic conversion of biomass. Chemical Society Reviews 2016, 45 (3), 584-611. $10.1039 / \mathrm{c} 5 \mathrm{cs} 00859 \mathrm{j}$.

$7 . \quad$ Dusselier, M.; Van Wouwe, P.; Dewaele, A.; Jacobs, P. A.; Sels, B. F., Shape-selective zeolite catalysis for bioplastics production. Science 2015, 349 (6243), 78-80. 10.1126/science.aaa7169.

8. Jacobs, P. A.; Dusselier, M.; Sels, B. F., Will ZeoliteBased Catalysis be as Relevant in Future Biorefineries as in Crude Oil Refineries? Angewandte Chemie International Edition 2014, 53 (33), 8621-8626. 10.1002/anie.201400922.

9. $\quad$ Taarning, E.; Osmundsen, C. M.; Yang, X. B.; Voss, B.; Andersen, S. I.; Christensen, C. H., Zeolite-catalyzed biomass conversion to fuels and chemicals. Energy \& Environmental Science 2011, 4 (3), 793-804. 10.1039/c004518g.

10. Kubička, D.; Kikhtyanin, O., Opportunities for zeolites in biomass upgrading-Lessons from the refining and petrochemical industry. Catalysis Today 2015, 243, 10-22. 10.1016/j.cattod.2014.07.043.

11. Luo, W. H.; Cao, W. X.; Bruijnincx, P. C. A.; Lin, L.; Wang, A. Q.; Zhang, T., Zeolite-supported metal catalysts for selective hydrodeoxygenation of biomass-derived platform molecules. Green Chemistry 2019, 21 (14), 3744-3768. $10.1039 / \mathrm{c} 9 \mathrm{gc0} 1216 \mathrm{~h}$.

12. Philippaerts, A.; Paulussen, S.; Breesch, A.; Turner, S.; Lebedev, O. I.; Van Tendeloo, G.; Sels, B.; Jacobs, P., Unprecedented Shape Selectivity in Hydrogenation of Triacylglycerol Molecules with Pt/ZSM-5 Zeolite. Angewandte Chemie International Edition 2011, 50 (17), 3947-3949. 10.1002/anie.201007513.

13. Jae, J.; Tompsett, G. A.; Foster, A. J.; Hammond, K. D.; Auerbach, S. M.; Lobo, R. F.; Huber, G. W., Investigation into the 
shape selectivity of zeolite catalysts for biomass conversion. Journal of Catalysis 2011, 279 (2), 257-268. 10.1016/j.jcat.2011.01.019.

14. Weisz, P. B.; Haag, W. O.; Rodewald, P. G., Catalytic production of high-grade fuel (gasoline) from biomass compounds by shape-selective catalysis. Science 1979, 206 (4414), 57-8. 10.1126/science.206.4414.57.

15. Mihalcik, D. J.; Mullen, C. A.; Boateng, A. A., Screening acidic zeolites for catalytic fast pyrolysis of biomass and its components. Journal of Analytical and Applied Pyrolysis 2011, 92 (1), 224-232. 10.1016/j.jaap.2011.06.001.

16. Cheng, Y. T.; Wang, Z.; Gilbert, C. J.; Fan, W.; Huber, G. W., Production of p-Xylene from Biomass by Catalytic Fast Pyrolysis Using ZSM-5 Catalysts with Reduced Pore Openings. Angewandte Chemie International Edition 2012, 51 (44), 11097 11100. 10.1002/anie.201205230.

17. Lew, C. M.; Rajabbeigi, N.; Tsapatsis, M., Tincontaining zeolite for the isomerization of cellulosic sugars. Microporous and Mesoporous Materials 2012, 153, 55-58. 10.1016/j.micromeso.2011.12.020.

18. Roman-Leshkov, Y.; Moliner, M.; Labinger, J. A.; Davis, M. E., Mechanism of Glucose Isomerization Using a Solid Lewis Acid Catalyst in Water. Angewandte Chemie International Edition 2010, 49 (47), 8954-8957. 10.1002/anie.201004689.

19. Perez-Ramirez, J.; Christensen, C. H.; Egeblad, K.; Christensen, C. H.; Groen, J. C., Hierarchical zeolites: enhanced utilisation of microporous crystals in catalysis by advances in materials design. Chemical Society Reviews 2008, 37 (11), 253042. 10.1039/b809030k.

20. Serrano, D. P.; Escola, J. M.; Pizarro, P., Synthesis strategies in the search for hierarchical zeolites. Chemical Society Reviews 2013, 42 (9), 4004-35. 10.1039/c2cs35330j.

21. Parlett, C. M.; Wilson, K.; Lee, A. F., Hierarchical porous materials: catalytic applications. Chemical Society Reviews 2013, 42 (9), 3876-93. 10.1039/c2cs35378d.

22. Li, J.; Li, X. Y.; Zhou, G. Q.; Wang, W.; Wang, C. W.; Komarneni, S.; Wang, Y. J., Catalytic fast pyrolysis of biomass with mesoporous ZSM-5 zeolites prepared by desilication with $\mathrm{NaOH}$ solutions. Applied Catal A: Genernal 2014, 470, 115-122. 10.1016/j.apcata.2013.10.040.

23. Nuttens, N.; Verboekend, D.; Deneyer, A.; Van Aelst, J.; Sels, B. F., Potential of Sustainable Hierarchical Zeolites in the Valorization of $\alpha$-Pinene. ChemSusChem 2015, 8 (7), 1197-1205. 10.1002/cssc.201403457.

24. Puértolas, B.; Veses, A.; Callén, M. S.; Mitchell, S.; García, T.; Pérez-Ramírez, J., Porosity-Acidity Interplay in Hierarchical ZSM-5 Zeolites for Pyrolysis Oil Valorization to Aromatics. ChemSusChem 2015, 8 (19), 3283-3293. 10.1002/cssc. 201500685 .

25. Van Aelst, J.; Verboekend, D.; Philippaerts, A.; Nuttens, N.; Kurttepeli, M.; Gobechiya, E.; Haouas, M.; Sree, S. P.; Denayer, J. F.; Martens, J. A.; Kirschhock, C. E. A.; Taulelle, F.; Bals, S.; Baron, G. V.; Jacobs, P. A.; Sels, B.F., Catalyst design by $\mathrm{NH} 4 \mathrm{OH}$ treatment of USY zeolite. Advanced Functional Materials 2015, 25 (46), 7130-7144. 10.1002/adfm.201502772.

26. Van Aelst, J.; Philippaerts, A.; Turner, S.; Van Tendeloo, G.; Jacobs, P. A.; Sels, B. F., Heterogeneous conjugation of vegetable oil with alkaline treated highly dispersed Ru/USY catalysts. Applied Catalysis A: General 2016, 526, 172-182. 10.1016/j.apcata.2016.08.026.

27. Christensen, C. H.; Johannsen, K.; Toernqvist, E.; Schmidt, I.; Topsoe, H.; Christensen, C. H., Mesoporous zeolite single crystal catalysts: Diffusion and catalysis in hierarchical zeolites. Catalysis Today 2007, 128 (3-4), 117-122. 10.1016/j.cattod.2007.06.082.

28. Christensen, C. H.; Johannsen, K.; Schmidt, I.; Christensen, C. H., Catalytic benzene alkylation over mesoporous zeolite single crystals: improving activity and selectivity with a new family of porous materials. Journal of the American Chemical Society 2003, 125 (44), 13370-1. 10.1021/ja037063c.

29. Fernandez, C.; Stan, I.; Gilson, J. P.; Thomas, K.; Vicente, A.; Bonilla, A.; Pérez-Ramírez, J., Hierarchical ZSM-5 Zeolites in Shape-Selective Xylene Isomerization: Role of Mesoporosity and Acid Site Speciation. Chemistry-A European Journal 2010, 16 (21), 6224-6233. 10.1002/chem.200903426.

30. Gamliel, D. P.; Cho, H. J.; Fan, W.; Valla, J. A., On the effectiveness of tailored mesoporous MFI zeolites for biomass catalytic fast pyrolysis. Applied Catalysis A: Genernal 2016, 522 , 109-119. 10.1016/j.apcata.2016.04.026.

31. Verboekend, D.; Perez-Ramirez, J., Design of hierarchical zeolite catalysts by desilication. Catalysis Science \& Technology 2011, l (6), 879-890. 10.1039/c1cy00150g.

32. Bai, R.; Song, Y.; Li, Y.; Yu, J., Creating Hierarchical Pores in Zeolite Catalysts. Trends in Chemistry 2019, 1 (6), 601611. 10.1016/j.trechm.2019.05.010.

33. Verboekend, D.; Vilé, G.; Pérez-Ramírez, J., Hierarchical Y and USY zeolites designed by post-synthetic strategies. Advanced Functional Materials 2012, 22 (5), 916-928. 10.1002/adfm.201102411.

34. Verboekend, D.; Perez-Ramirez, J., Towards a sustainable manufacture of hierarchical zeolites. ChemSusChem 2014, 7 (3), 753-64. 10.1002/cssc. 201301313.

35. Verboekend, D.; Mitchell, S.; Milina, M.; Groen, J. C.; Perez-Ramirez, J., Full Compositional Flexibility in the Preparation of Mesoporous MFI Zeolites by Desilication. The Journal of Physical Chemistry C 2011, 115 (29), 14193-14203. 10.1021/jp201671s.

36. Verboekend, D.; Nuttens, N.; Locus, R.; Van Aelst, J.; Verolme, P.; Groen, J.; Pérez-Ramírez, J.; Sels, B. F., Synthesis, characterisation, and catalytic evaluation of hierarchical faujasite zeolites: milestones, challenges, and future directions. Chemical Society Reviews 2016, 45 (12), 3331-3352. 10.1039/C5CS00520E. 37. Li, K.; Valla, J.; Garcia-Martinez, J., Realizing the commercial potential of hierarchical zeolites: new opportunities in catalytic cracking. ChemCatChem 2014, 6 (1), 46-66. 10.1002/cctc. 201300345.

38. Shi, N.; Liu, Q. Y.; Zhang, Q.; Wang, T. J.; Ma, L. L., High yield production of 5-hydroxymethylfurfural from cellulose by high concentration of sulfates in biphasic system. Green Chemistry 2013, 15 (7), 1967-1974. 10.1039/c3gc40667a.

39. Liao, Y. H.; Liu, Q. Y.; Wang, T. J.; Long, J. X.; Ma, L. L.; Zhang, Q., Zirconium phosphate combined with $\mathrm{Ru} / \mathrm{C}$ as a highly efficient catalyst for the direct transformation of cellulose to C-6 alditols. Green Chemistry 2014, 16 (6), 3305-3312. $10.1039 / \mathrm{c} 3 \mathrm{gc} 42444 \mathrm{~h}$.

40. Liu, Y.; Chen, L. G.; Wang, T. J.; Zhang, Q.; Wang, C. G.; Yan, J. Y.; Ma, L. L., One-Pot Catalytic Conversion of Raw Lignocellulosic Biomass into Gasoline Alkanes and Chemicals over LiTaMoO6 and $\mathrm{Ru} / \mathrm{C}$ in Aqueous Phosphoric Acid. ACS Sustainable Chemistry \& Engineering 2015, 3 (8), 1745-1755. 10.1021/acssuschemeng.5b00256.

41. Liao, Y.; de Beeck, B. O.; Thielemans, K.; Ennaert, T.; Snelders, J.; Dusselier, M.; Courtin, C. M.; Sels, B. F., The role of pretreatment in the catalytic valorization of cellulose. Molecular Catalysis 2020, 487, 110883. j.mcat.2020.110883.

42. Mika, L. T.; Csefalvay, E.; Nemeth, A., Catalytic Conversion of Carbohydrates to Initial Platform Chemicals: Chemistry and Sustainability. Chemical Reviews 2018, 118 (2), 505-613. 10.1021/acs.chemrev.7b00395.

43. Schutyser, W.; Renders, T.; Van den Bosch, S.; Koelewijn, S. F.; Beckham, G. T.; Sels, B. F., Chemicals from lignin: an interplay of lignocellulose fractionation, depolymerisation, and upgrading. Chemical Society Reviews 2018, 47 (3), 852-908. 10.1039/c7cs00566k. 
44. Zhang, X.; Zhang, Q.; Wang, T.; Ma, L.; Yu, Y.; Chen, L., Hydrodeoxygenation of lignin-derived phenolic compounds to hydrocarbons over $\mathrm{Ni} / \mathrm{SiO} 2-\mathrm{ZrO} 2$ catalysts. Bioresource Technology 2013, 134, 73-80. 10.1016/j.biortech.2013.02.039.

45. Tuck, C. O.; Perez, E.; Horvath, I. T.; Sheldon, R. A.; Poliakoff, M., Valorization of biomass: deriving more value from waste. Science 2012, 337 (6095), 695-9. 10.1126/science.1218930. 46. Yu, Y. Q.; Li, X. Y.; Su, L.; Zhang, Y.; Wang, Y. J.; Zhang, H. Z., The role of shape selectivity in catalytic fast pyrolysis of lignin with zeolite catalysts. Applied Catalysis A: Genernal 2012, 447, 115-123. 10.1016/j.apcata.2012.09.012.

47. Van den Bosch, S.; Schutyser, W.; Vanholme, R.; Driessen, T.; Koelewijn, S.-F.; Renders, T.; De Meester, B.; Huijgen, W.; Dehaen, W.; Courtin, C.; Lagrain, B.; Boerjan, W.; Sels, B. F., Reductive lignocellulose fractionation into soluble lignin-derived phenolic monomers and dimers and processable carbohydrate pulps. Energy \& Environmental Science 2015, 8 (6), 1748-1763. 10.1039/C5EE00204D

48. $\quad$ Anderson, E. M.; Katahira, R.; Reed, M.; Resch, M. G.; Karp, E. M.; Beckham, G. T.; Roman-Leshkov, Y., Reductive Catalytic Fractionation of Corn Stover Lignin. ACS Sustainable Chemistry \& Engineering 2016, 4 (12), 6940-6950. 10.1021/acssuschemeng.6b01858.

49. Galkin, M. V.; Samec, J. S. M., Lignin Valorization through Catalytic Lignocellulose Fractionation: A Fundamental Platform for the Future Biorefinery. ChemSusChem 2016, 9 (13), 1544-1558. 10.1002/cssc.201600237.

50. Anderson, E. M.; Stone, M. L.; Katahira, R.; Reed, M.; Beckham, G. T.; Roman-Leshkov, Y., Flowthrough Reductive Catalytic Fractionation of Biomass. Joule 2017, 1 (3), 613-622. 10.1016/j.joule.2017.10.004.

51. Kumaniaev, I.; Subbotina, E.; Savmarker, J.; Larhed, M.; Galkin, M. V.; Samec, J. S. M., Lignin depolymerization to monophenolic compounds in a flow-through system. Green Chemistry 2017, 19 (24), 5767-5771. 10.1039/c7gc02731a.

52. Renders, T.; Van den Bosch, S.; Koelewijn, S. F.; Schutyser, W.; Sels, B. F., Lignin-first biomass fractionation: the advent of active stabilisation strategies. Energy \& Environmental Science 2017, 10 (7), 1551-1557. 10.1039/c7ee01298e.

53. Anderson, E. M.; Stone, M. L.; Hulsey, M. J.; Beckham, G. T.; Roman-Leshkov, Y., Kinetic Studies of Lignin Solvolysis and Reduction by Reductive Catalytic Fractionation Decoupled in Flow-Through Reactors. ACS Sustainable Chemistry \& $\begin{array}{lllll}\text { Engineering } & \mathbf{2 0 1 8}, & 6 & \text { (6), }\end{array}$ 10.1021/acssuschemeng.8b01256.

54. Van den Bosch, S.; Schutyser, W.; Koelewijn, S. F.; Renders, T.; Courtin, C. M.; Sels, B. F., Tuning the lignin oil OHcontent with $\mathrm{Ru}$ and $\mathrm{Pd}$ catalysts during lignin hydrogenolysis on birch wood. Chemical Communications 2015, 51 (67), 13158-61. $10.1039 / \mathrm{c} 5 \mathrm{cc} 04025 \mathrm{f}$.

55. Renders, T.; Schutyser, W.; Van den Bosch, S.; Koelewijn, S. F.; Vangeel, T.; Courtin, C. M.; Sels, B. F., Influence of Acidic (H3PO4) and Alkaline $(\mathrm{NaOH})$ Additives on the Catalytic Reductive Fractionation of Lignocellulose. ACS Catalysis 2016, 6 (3), 2055-2066. 10.1021/acscatal.5b02906.

56. Sun, J. K.; Li, H. L.; Xiao, L. P.; Guo, X.; Fang, Y. M.; Sun, R. C.; Song, G. Y., Fragmentation of Woody Lignocellulose into Primary Monolignols and Their Derivatives. ACS Sustainable Chemistry \& Engineering 2019, 7 (5), 4666-4674. 10.1021/acssuschemeng.8b04032.

57. Schutyser, W.; Van den Bosch, S.; Renders, T.; De Boe, T.; Koelewijn, S. F.; Dewaele, A.; Ennaert, T.; Verkinderen, O.; Goderis, B.; Courtin, C. M.; Sels, B. F., Influence of bio-based solvents on the catalytic reductive fractionation of birch wood. Green Chemistry 2015, 17 (11), 5035-5045. 10.1039/c5gc01442e. 58. Van den Bosch, S.; Renders, T.; Kennis, S.; Koelewijn, S.-F.; Van den Bossche, G.; Vangeel, T.; Deneyer, A.; Depuydt,
D.; Courtin, C.; Thevelein, J.; Schutyser, W.; Sels, B. F., Integrating lignin valorization and bio-ethanol production: on the role of Ni-Al2O3 catalyst pellets during lignin-first fractionation. Green Chemistry 2017, 19 (14), 3313-3326. $10.1039 / \mathrm{C} 7 \mathrm{GC} 01324 \mathrm{H}$.

59. $\quad$ Song, Q.; Wang, F.; Cai, J.; Wang, Y.; Zhang, J.; Yu, W.; $\mathrm{Xu}$, J., Lignin depolymerization (LDP) in alcohol over nickel-based catalysts via a fragmentation-hydrogenolysis process. Energy \& Environmental Science 2013, 6 (3), 994-1007. 10.1039/C2EE23741E.

60. Renders, T.; Van den Bossche, G.; Vangeel, T.; Van Aelst, K.; Sels, B. F., Reductive catalytic fractionation: state of the art of the lignin-first biorefinery. Current Opinion in Biotechnology 2017, 56, 193-201. 10.1016/j.copbio.2018.12.005.

61. Parsell, T.; Yohe, S.; Degenstein, J.; Jarrell, T.; Klein, I.; Gencer, E.; Hewetson, B.; Hurt, M.; Kim, J. I.; Choudhari, H.; Saha, B.; Meilan, R.; Mosier, N.; Ribeiro, F.; Delgass, W. N.; Chapple, C.; Kenttamaa, H. I.; Agrawal, R.; Abu-Omar, M. M., A synergistic biorefinery based on catalytic conversion of lignin prior to cellulose starting from lignocellulosic biomass. Green Chemistry 2015, 17 (3), 1492-1499. 10.1039/c4gc01911c.

62. Zhu, Y. T.; Liao, Y. H.; Lv, W.; Liu, J.; Song, X. B.; Chen, L. G.; Wang, C. G.; Sels, B. F.; Ma, L. L., Complementing Vanillin and Cellulose Production by Oxidation of Lignocellulose with Stirring Control. ACS Sustainable Chemistry \& Engineering 2020, 8 (6), 2361-2374. 10.1021/acssuschemeng.9b04837.

63. Renders, T.; Cooreman, E.; Van den Bosch, S.; Schutyser, W.; Koelewijn, S. F.; Vangeel, T.; Deneyer, A.; Van den Bossche, G.; Courtin, C. M.; Sels, B. F., Catalytic lignocellulose biorefining in n-butanol/water: a one-pot approach toward phenolics, polyols, and cellulose. Green Chemistry 2018, 20 (20), 4607-4619. 10.1039/c8gc01031e.

64. Wu, X. J.; Fan, X. T.; Xie, S. J.; Lin, J. C.; Cheng, J.; Zhang, Q. H.; Chen, L. Y.; Wang, Y., Solar energy-driven ligninfirst approach to full utilization of lignocellulosic biomass under mild conditions. Nature Catalysis 2018, 1 (10), 772-780. 10.1038/s41929-018-0148-8.

65. Liu, X.; Li, H. L.; Xiao, L. P.; Sun, R. C.; Song, G. Y., Chemodivergent hydrogenolysis of eucalyptus lignin with Ni@ZIF-8 catalyst. Green Chemistry 2019, 21 (6), 1498-1504. $10.1039 / \mathrm{c} 8 \mathrm{gc} 03511 \mathrm{c}$.

66. Vangeel, T.; Renders, T.; Van Aetst, K.; Cooreman, E.; Van den Bosch, S.; Van den Bossche, G.; Koelewijn, S. F.; Courtin, C. M.; Sels, B. F., Reductive catalytic fractionation of black locust bark. Green Chemistry 2019, 21 (21), 5841-5851. $10.1039 / \mathrm{c} 9 \mathrm{gc} 02139 \mathrm{f}$.

67. Anderson, E. M.; Stone, M. L.; Katahira, R.; Reed, M.; Muchero, W.; Ramirez, K. J.; Beckham, G. T.; Román-Leshkov, Y., Differences in S/G ratio in natural poplar variants do not predict catalytic depolymerization monomer yields. Nature Communications 2019, 10 (1), 1-10. 10.1038/s41467-019-099861.

68. Verboekend, D.; Liao, Y. H.; Schutyser, W.; Sels, B. F., Alkylphenols to phenol and olefins by zeolite catalysis: a pathway to valorize raw and fossilized lignocellulose. Green Chemistry 2016, 18 (1), 297-306. 10.1039/c5gc01868d.

69. Liao, Y. H.; d'Halluin, M.; Makshina, E.; Verboekend, D.; Sels, B. F., Shape selectivity vapor-phase conversion of ligninderived 4-ethylphenol to phenol and ethylene over acidic aluminosilicates: Impact of acid properties and pore constraint. Applied Catalysis B: Environmental 2018, 234, 117-129. 10.1016/j.apcatb.2018.04.001.

70. Liao, Y. H.; Zhong, R. Y.; Makshina, E.; d'Halluin, M.; van Limbergen, Y.; Verboekend, D.; Sels, B. F., Propylphenol to Phenol and Propylene over Acidic Zeolites: Role of Shape Selectivity and Presence of Steam. ACS Catalysis 2018, 8 (9), 7861-7878. 10.1021/acscatal.8b01564. 
71. Liao, Y.; Koelewijn, S.-F.; Van den Bossche, G.; Van Aelst, J.; Van den Bosch, S.; Renders, T.; Navare, K.; Nicolaï, T.; Van Aelst, K.; Maesen, M., A sustainable wood biorefinery for low-carbon footprint chemicals production. Science 2020, 367 (6484), 1385-1390. 10.1126/science.aau1567.

72. $\quad$ Liu, X.; Wang, C.; Zhang, Y.; Qiao, Y.; Pan, Y.; Ma, L., Selective Preparation of 4-Alkylphenol from Lignin-Derived Phenols and Raw Biomass over Magnetic Co-Fe@ N-Doped Carbon Catalysts. ChemSusChem 2019, 12 (21), 4791-4798. $10.1002 /$ cssc. 201901578.

73. Aguayo, A. T.; Gayubo, A. G.; Tarrío, A. M.; Atutxa, A.; Bilbao, J., Study of operating variables in the transformation of aqueous ethanol into hydrocarbons on an HZSM-5 zeolite. Journal of Chemical Technology \& Biotechnology 2002, 77 (2), 211-216. 10.1002/jctb.540.

74. Mitchell, S.; Pinar, A. B.; Kenvin, J.; Crivelli, P.; Karger, J.; Perez-Ramirez, J., Structural analysis of hierarchically organized zeolites. Nature Communications 2015, 6, 8633. 10.1038/ncomms9633.

75. Milina, M.; Mitchell, S.; Michels, N. L.; Kenvin, J.; Perez-Ramirez, J., Interdependence between porosity, acidity, and catalytic performance in hierarchical ZSM-5 zeolites prepared by post-synthetic modification. Journal of Catalysis 2013, 308, 398407. 10.1016/j.jcat.2013.08.020.

76. Derouane, E. G.; Vedrine, J. C.; Pinto, R. R.; Borges, P. M.; Costa, L.; Lemos, M. A. N. D. A.; Lemos, F.; Ribeiro, F. R., The Acidity of Zeolites: Concepts, Measurements and Relation to Catalysis: A Review on Experimental and Theoretical Methods for the Study of Zeolite Acidity. Catalysis Reviews 2013, 55 (4), 454515. 10.1080/01614940.2013.822266.

77. Verboekend, D.; Pérez-Ramírez, J., Desilication Mechanism Revisited: Highly Mesoporous All-Silica Zeolites Enabled Through Pore-Directing Agents. Chemistry-A European Journal 2011, 17 (4), 1137-1147. 10.1002/chem.201002589.

78. Groen, J. C.; Peffer, L. A.; Moulijn, J. A.; Pérez-Ramírez, J., Mechanism of hierarchical porosity development in MFI zeolites by desilication: The role of aluminium as a pore-directing agent. Chemistry-A European Journal 2005, 11 (17), 4983-4994. 10.1002/chem.200500045.

79. Schneider, P.; Kraus, M.; Bažant, V., Catalytic dealkylation of alkylaromatic compounds. V. Dealkylation kinetics of higher alkylphenols over an acidic catalyst. Collection of Czechoslovak Chemical Communications 1962, 27 (1), 9-16. 10.1135/cccc19620009.

80. Shi, J.; Wang, Y.; Yang, W.; Tang, Y.; Xie, Z., Recent advances of pore system construction in zeolite-catalyzed chemical industry processes. Chemical Society Reviews 2015, 44 (24), 8877 903. 10.1039/c5cs00626k.

81. Danilina, N.; Krumeich, F.; van Bokhoven, J. A., Hierarchical SAPO-5 catalysts active in acid-catalyzed reactions. Journal of Catalysis 2010, 272 (1), 37-43. 10.1016/j.jcat.2010.03.014.

82. Bourdillon, G.; Gueguen, C.; Guisnet, M., Characterization of acid catalysts by means of model reactions: I. Acid strength necessary for the catalysis of various hydrocarbon reactions. Applied Catalysis 1990, 61 (1), 123-139. 10.1016/S0166-9834(00)82139-9.

83. Reyes, S. C.; Scriven, L. E., Analysis of Zeolite Catalyst Deactivation during Catalytic Cracking Reactions. Industrial \& Engineering Chemistry Research 1991, 30 (1), 71-82. DOI 10.1021/ie00049a011.

84. Santacesaria, E.; Di Serio, M.; Ciambelli, P.; Gelosa, D.; Carra, S., Catalytic alkylation of phenol with methanol: Factors influencing activities and selectivities: II. Effect of intracrystalline diffusion and shape selectivity on H-ZSM5 zeolite. Applied Catalysis 1990, 64, 101-117. 10.1016/S0166-9834(00)81556-0.

85. Wang, Q.; Giannetto, G.; Guisnet, M., Dealumination of zeolites III. Effect of extra-framework aluminum species on the activity, selectivity, and stability of $\mathrm{Y}$ zeolites in n-heptane cracking. Journal of Catalysis 1991, 130 (2), 471-482. 10.1016/0021-9517(91)90129-R.

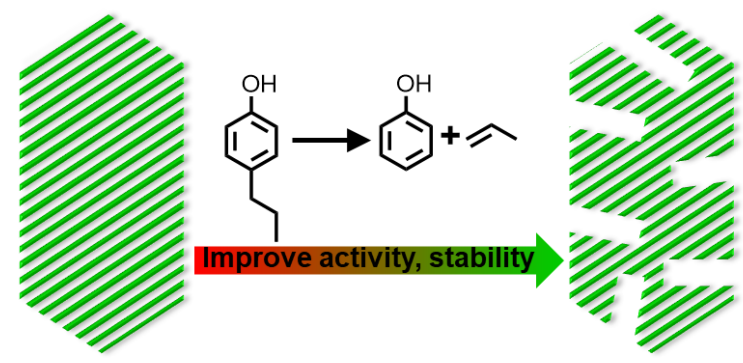

Microporous ZSM-5

Hierarchical ZSM-5

Hierarchization of ZSM-5 improves the catalytic activity and stability for the selective dealkylation of lignin-derived alkylphenol to phenol and olefin. 